\title{
Anti-Gastric Ulcer Activity of the Water Extract from Payawanorn (Pseuderanthemum Palatiferum)
}

Kannika Inchab, B.Pharm. ${ }^{1,2}$, Parirat Khonsung, Ph.D. ${ }^{3}$, Natthakarn Chiranthanut, Ph.D. ${ }^{3}$, Puongtip Kunanusorn, Ph.D. ${ }^{3}$, Saranyapin Potikanond, M.D., Ph.D. ${ }^{3}$, Sunee Chansakaow, Ph.D. ${ }^{4}$, Ampai Panthong, Ph.D. ${ }^{3}$, Seewaboon Sireeratawong, Ph.D. ${ }^{3}$

${ }^{1}$ Student in Graduate School, Department of Pharmacology, Faculty of Medicine, Chiang Mai University, Mueang, Chiang Mai 50200, Thailand.

${ }^{2}$ Department of Pharmaceutical Care, Faculty of Pharmacy, Payap University, Mueang, Chiang Mai 50000, Thailand. ${ }^{3}$ Department of Pharmacology, Faculty of Medicine, ${ }^{4}$ Department of Pharmaceutical Sciences, Faculty of Pharmacy, Chiang Mai University, Mueang, Chiang Mai 50200, Thailand.

Received 5 May 2017 • Accepted 19 June 2017 • Published online 24 May 2018

\section{Abstract:}

Objective: To examine the anti-gastric ulcer activity of Payawanorn (Psuderanthemum palatiferum) water extract (PPE) in rats. Material and Methods: Evaluation of anti-gastric ulcer activity of PPE was performed using three induced gastric ulcers models: (1) ethanol/hydrochloric acid $(\mathrm{EtOH} / \mathrm{HCl})$, (2) restraint water immersion stress and (3) indomethacin. Ulcer indices were determined by microscopic examination (10X). Pylorus ligation and gastric-wall mucus determination were used to investigate the mechanism of anti-gastric ulcer activity of PPE.

Results: Oral administration of PPE (150, 300 and $600 \mathrm{mg} / \mathrm{kg})$ significantly inhibited gastric ulcer formation induced by $\mathrm{EtOH} / \mathrm{HCl}$, by water immersion restraint stress, and by indomethacin in rats ( $p$-value<0.05). PPE at $600 \mathrm{mg} / \mathrm{kg}$ showed a high percent inhibition of gastric ulcer formation in all models. In the pylorus-ligated model, pretreatment with PPE had no effect on $\mathrm{pH}$, acidity output or the gastric acid secretion rate, demonstrating that PPE lacks an anti-secretory effect. Gastric wall mucus was markedly preserved by pretreatment PPE at $600 \mathrm{mg} / \mathrm{kg}(18.91 \pm 2.57 \mathrm{\mu g}$ alcian blue/g wet stomach) after ethanol-induced ulcer when compared to that the control group (12.38 $\pm 1.02 \mu \mathrm{g}$ alcian blue/ $\mathrm{g}$ wet stomach). Conclusion: PPE possesses an anti-gastric ulcer effect related to the preservation of gastric mucus, supporting the traditional use of $P$. palatiferum to treat gastric ulcers.

Keywords: anti-gastric ulcer, gastric-wall mucus, Pseuderanthemum palatiferum, pylorus ligation 


\section{Introduction}

Pseuderanthemum palatiferum (P. palatiferum) (family Acanthaceae) originated in Vietnam; it is used as a traditional medicine in Thailand. Its vernacular names include Hoanngoc or Xuan-hoa in Vietnamese and Payawanorn in Thai. ${ }^{1}$ It is used to treat or prevent several symptoms and diseases such as wounds, hemorrhoids, trauma, colitis, hypertension, diarrhea, arthritis, rheumatoid, pharyngitis, inflammatory bowel diseases, dysentery, constipation, influenza or colds, hepatitis, peptic ulcer, tumor, nephritis, and diabetes among others. ${ }^{2-5}$

Triterpenoid saponin, flavonoid and several compounds from the leaves of $P$. palatiferum have been reported such as $\beta$-sitosterol, stigmasterol, kaempferol, apiginin, salicylic acid, phytol, essential amino acids (lysine, methionine, threonine), minerals (calcium, potassium, magnesium, iron), and volatile substances (2-pyrrolidinone, 2-pipridinone, 4-ethyl-2-methoxyphenol, megastigmatrienone 4, 1,2,4-triethyl-5-methyl-benzene, hexadecanoic acid, octadecatrienoic acid methyl ester, and phytol). ${ }^{3,4,6,7}$ Of these, flavonoids have been demonstrated to have gastroprotective properties. $^{8}$ Supporting data for the anti-gastric ulcer activity of $P$. palatiferum, however, are limited. The objective of this study was to examine the anti-gastric ulcer activity of $P$. palatiferum water extract (PPE) in rats.

\section{Material and Methods}

\section{Plant material and extract preparation}

Fresh $P$. palatiferum leaves were collected in Chiang Mai province. The plant voucher specimen was located in the Queen Sirikit Botanic Garden Herbarium (BQG 42335). The fresh leaves were washed, minced and immersed in distilled water for 24 hour (hr). The crude extract of $P$. palatiferum was collected by filtration, evaporated at $60-70{ }^{\circ} \mathrm{C}$ and then lyophilized. The yield was approximately $6 \%(w / w)$.

\section{Experimental animals}

Male Sprague-Dawley rats, 200-250 g, were purchased from the National Laboratory Animal Center, Mahidol University, Salaya, Nakorn Pathom Province, Thailand. The rats were kept in an animal room at controlled conditions of $24+1{ }^{\circ} \mathrm{C}, 50.0 \pm 10.0 \%$ relative humidity and a $12 \mathrm{hr}$ light-12 hr dark cycle for at least one week before starting the experiments. The rats had free access to food as well as to water. All animal protocols were approved by The Animal Ethics Committee of the Faculty of Medicine, Chiang Mai University, Thailand (20/2557).

\section{Drugs}

Drugs used in the study were indomethacin (Sigma, St. Louis, USA), cimetidine (Sigma, St. Louis, USA), misoprostol (Pfizer, NY, USA), pentobarbital sodium (Sante Animale, Liboure, France). All test drugs except pentobarbital sodium were dissolved in distilled water. Drugs were orally administered in a volume of $0.5 \mathrm{~mL} / 100 \mathrm{~g}$ of body weight.

\section{Experimental protocol Investigation of anti-gastric ulcer activity}

Rats in the anti-gastric ulcer activity study were fasted for $48 \mathrm{hr}$ but allowed water ad libitum. Water was withdrawn $1 \mathrm{hr}$ before starting the experiment. The rats were divided into 5 groups of 6 . Each group received an oral dose of distilled water, cimetidine $(100 \mathrm{mg} / \mathrm{kg})$ or PPE (150, $300,600 \mathrm{mg} / \mathrm{kg}$ ) $1 \mathrm{hr}$ before the induction of gastric ulcers.

Gastric ulcers were induced by one of three methods. The first method involved ethano//hydrochloric acid $(\mathrm{EtOH} / \mathrm{HCl})$ to induce ulcers. ${ }^{9,10}$ Each of the 6 rats in this group was orally administrated $1 \mathrm{~mL}$ of $\mathrm{EtOH} / \mathrm{HCl}$. The rats were sacrificed $1 \mathrm{hr}$ later and the extent of gastric ulcers was determined. The second method involved restraint water immersion stress-induced gastric ulcers. ${ }^{11,12}$ Each of the 6 rats in this group was placed in separate 
compartments of a stainless-steel cage which was immersed up to the level of the xiphoid in a water-bath maintained at $22 \pm 2{ }^{\circ} \mathrm{C}$ for $5 \mathrm{hr}$ to induce stress ulcers. After $5 \mathrm{hr}$ the rats were sacrificed and the extent of gastric ulcers was determined. The third method involved indomethacininduced gastric ulcers. ${ }^{13,14}$ In this group, indomethacin at a dose of $100 \mathrm{mg} / \mathrm{kg}$ was orally administrated to each of the 6 rats in this group. Five hours later the rats were sacrificed and the extent of gastric ulcers was determined.

The stomachs of all the sacrificed rats from each of the three groups were removed and opened along the greater curvature to determine the extent of gastric ulcers using a dissecting microscope (10X). The extent of the gastric ulcers was evaluated by measuring the length of the lesion in millimeters (min) then the ulcer index and percent inhibition of gastric ulcer were calculated as the following formulae:

$$
\begin{aligned}
& \text { Ulcer index }=\frac{\sum \text { Total lengths of lesion in each group }}{\text { Numbers of rats in that group }} \\
& \% \text { Inhibition }=\frac{{\text { Ulcer } \text { index }_{\text {control }}-\text { Ulcer index }}_{\text {treated }}}{\text { Ulcer index control }_{100}} \times 100
\end{aligned}
$$

Investigation of the anti-gastric ulcer activity

\section{mechanism}

The mechanism of anti-gastric ulcer activity was investigated using two investigative methods, pylorus ligation $^{15,16}$ and gastric-wall mucus determination. ${ }^{17,18}$

With pylorus ligation, 18 rats were divided into 3 groups of 6 rats each and orally given distilled water, cimetidine (100 mg/kg) or PPE (600 mg/kg) $1 \mathrm{hr}$ before pylorus ligation. Five hours after ligation, the rats were sacrificed and the gastric contents were collected, centrifuged at 2,500 rpm for $5 \mathrm{~min}$ and the volume measured. The total acidity of the supernatant was determined by titration with $0.1 \mathrm{~N} \mathrm{NaOH}$ to an end point of $\mathrm{pH} 7.4$ using phenolphthalein as an indicator.
For gastric-wall mucus determination, another group of 42 rats were divided into 7 groups of 6 rats each. Rats in groups 1 (distilled water) and 2 (PPE, $600 \mathrm{mg} / \mathrm{kg}$ ) were not subjected to gastric ulcer induction, while rats in groups 3-7 were given $1 \mathrm{~mL}$ of $\mathrm{EtOH} / \mathrm{HCl}$. Rats in groups 3-7 were orally pretreated with either distilled water, misoprostol $(100 \mu \mathrm{g} / \mathrm{kg})$, PPE $(150,300$ or $600 \mathrm{mg} / \mathrm{kg}$ ) $1 \mathrm{hr}$ before gastric ulcer induction. One hour after gastric ulcer induction, all rats were sacrificed and the stomachs were removed, opened, rinsed with normal saline and weighed, then immersed in alcian blue solution $(0.1 \% \mathrm{w} / \mathrm{v})$ for $2 \mathrm{hr}$. The excessive dye was removed with $0.25 \mathrm{M}$ sucrose solution. The dye complex, including gastric wall mucus, was extracted by immersion in $10 \mathrm{~mL}$ of $0.5 \mathrm{M}$ magnesium chloride for $2 \mathrm{hr}$. An equal volume of diethyl ether was then added to the blue extract and the emulsion was centrifuged at 2,500 rpm for $15 \mathrm{~min}$. The optical density of alcian blue in the aqueous layer was determined using a spectrophotometer at a wavelength of $580 \mathrm{~nm}$. The quantity of alcian blue extract per unit weight $(\mathrm{g})$ of wet stomach was calculated using a standard curve for concentration and absorbance of alcian blue.

\section{Statistical analysis}

Statistical evaluation of the differences in means between the groups was conducted using one-way analysis of variance and the post hoc least-significant difference test. $\mathrm{P}$-values less than 0.05 were considered significant. Data are expressed asmean \pm standard error of the mean (S.E.M).

\section{Results}

\section{Investigation of anti-gastric ulcer activity}

PPE (150, 300, and $600 \mathrm{mg} / \mathrm{kg}$ ) and cimetidine (100 mg/kg) significantly reduced gastric ulcer formation caused by all inducers compared to those of control group (Table 1). The ulcer index of rats pretreated with PPE at 
a dose of $600 \mathrm{mg} / \mathrm{kg}$ was similar to that of cimetidine in the $\mathrm{EtOH} / \mathrm{HCl}$ - and indomethacin-induced gastric ulcer experiments ( $p$-value>0.05). Inhibition of gastric ulcers by PPE was dose-dependent manner in all three models (Figure 1).

Investigation of the anti-gastric ulcer activity mechanism

In the pylorus-ligated model, the effect of PPE at a high dose $(600 \mathrm{mg} / \mathrm{kg})$ and of cimetidine $(100 \mathrm{mg} / \mathrm{kg})$ on gastric volume, gastric $\mathrm{pH}$, total acidity, and gastric acid secretion are shown in Table 2. Cimetidine, an antisecretory drug, reduced gastric volume, total acidity, and gastric acid secretion rate while gastric $\mathrm{pH}$ was increased. In the PPE-treated group, however, gastric $\mathrm{pH}$, total acidity, and gastric acid secretion rate did not differ from the control group. Pretreatment with PPE significantly decreased only gastric volume compared to that of control group ( $p$-value $<0.05$ ).

Table 1 Effects of Pseuderanthemum palatiferum extract on gastric ulcer formation in rats in three models

\begin{tabular}{llll}
\hline \multirow{2}{*}{ Group } & \multicolumn{2}{c}{ Ulcer index $(\mathrm{mm})$} \\
\cline { 2 - 4 } & EtOH/HCl & Stress & Indomethacin \\
\hline Control & $110.6 \pm 6.5$ & $15.6 \pm 1.2$ & $8.6 \pm 0.7$ \\
Cimetidine $100 \mathrm{mg} / \mathrm{kg}$ & $49.8 \pm 1.5^{*}$ & $0.6 \pm 0.1^{*}$ & $1.3 \pm 0.1^{*}$ \\
PPE $150 \mathrm{mg} / \mathrm{kg}$ & $88.2 \pm 1.3^{*}$ & $9.2 \pm 0.3^{*}$ & $4.4 \pm 0.2^{*}$ \\
PPE $300 \mathrm{mg} / \mathrm{kg}$ & $64.2 \pm 2.0^{*}$ & $7.3 \pm 0.3^{*}$ & $2.8 \pm 0.3^{*}$ \\
PPE $600 \mathrm{mg} / \mathrm{kg}$ & $59.5 \pm 4.4^{*}$ & $4.4 \pm 0.3^{*}$ & $2.0 \pm 0.4^{*}$ \\
\hline
\end{tabular}

Data are expressed as mean \pm S.E.M. $(n=6)$

*significantly different from control group ( $p$-value<0.05)

$\mathrm{EtOH}=$ ethanol, $\mathrm{HCl}=$ hydrochloric acid, $\mathrm{PPE}=$ Psuderanthemum palatiferum water extract

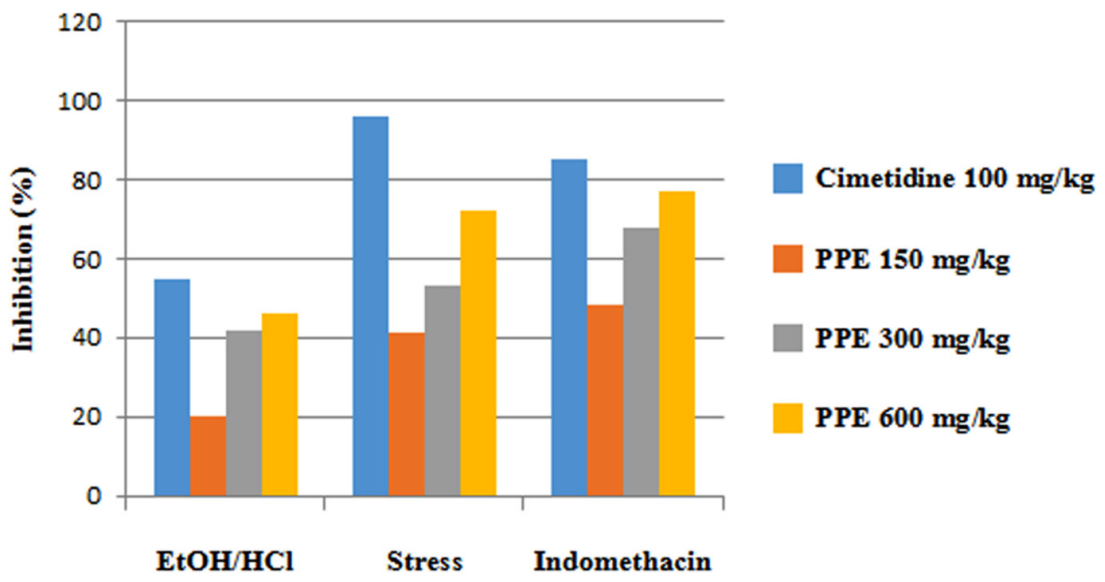

Figure 1 Pseuderanthemum palatiferum gastric ulcer inhibition in rats in three models 
The effect of PPE and misoprostol on the quantity of gastric wall mucus is shown in Figure 2. $\mathrm{EtOH} / \mathrm{HCl}$ resulted in a significant reduction of gastric wall mucus in the control group compared with the normal group (without $\mathrm{EtOH} / \mathrm{HCl})$. Pretreatment with misoprostol $(100 \mu \mathrm{g} / \mathrm{kg}$ a PGE1 analogue) or PPE (600 mg/kg) significantly protected gastric wall mucus from the effect of $\mathrm{EtOH} / \mathrm{HCl}$. Additionally, the gastric wall mucus value of rats pretreated with PPE at a dose of $600 \mathrm{mg} / \mathrm{kg}$ without gastric ulcer induction was similar to that of the normal rats.

Table 2 Effects of Pseuderanthemum palatiferum extract on gastric secretion in rats

\begin{tabular}{lllll}
\hline Group & $\begin{array}{l}\text { Gastric volume } \\
(\mathbf{m L} / 100 \mathbf{~ g})\end{array}$ & Gastric $\mathbf{p H}$ & Total acidity $(\mathbf{m E q})$ & $\begin{array}{l}\text { Gastric acid secretion } \\
\text { rate }(\mathbf{m L} / 100 \mathrm{~g} / \mathbf{h})\end{array}$ \\
\hline Control & $2.8 \pm 0.1$ & $1.2 \pm 0.0$ & $120.0 \pm 4.5$ & 0.6 \\
Cimetidine $100 \mathrm{mg} / \mathrm{kg}$ & $1.2 \pm 0.1^{*}$ & $7.3 \pm 0.3^{*}$ & $18.0 \pm 4.0^{*}$ & 0.2 \\
PPE $600 \mathrm{mg} / \mathrm{kg}$ & $2.4 \pm 0.1^{*}$ & $1.6 \pm 0.1$ & $107.0 \pm 8.0$ & 0.5 \\
\hline
\end{tabular}

Data are expressed as mean \pm S.E.M. $(n=6)$

*significantly different from control group ( $p$-value $<0.05)$

$\mathrm{PPE}=$ Psuderanthemum palatiferum water extract

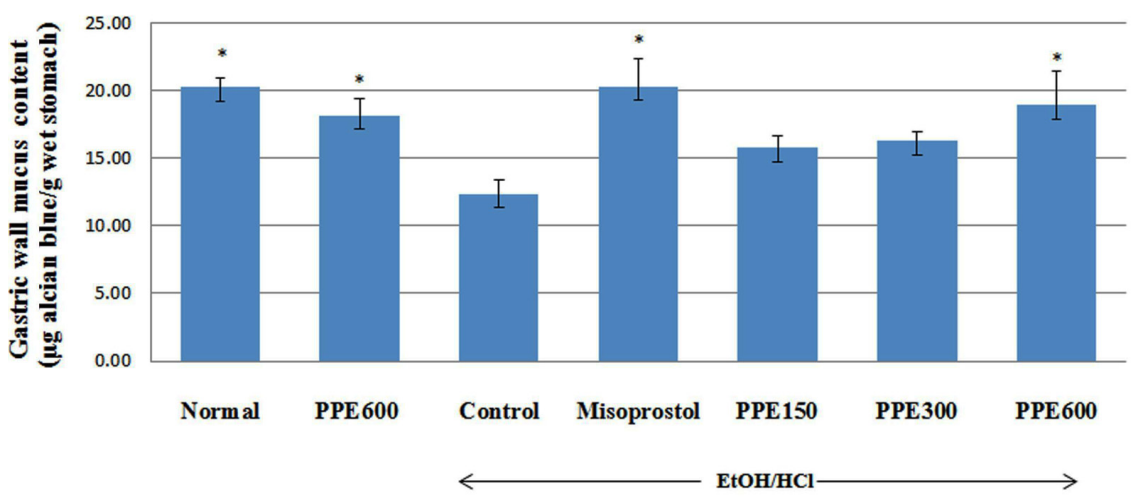

Data are expressed as mean \pm S.E.M. $(n=6)$

*significantly different from control group ( $p$-value<0.05)

Figure 2 Effects of Pseuderanthemum palatiferum extract on gastric wall mucus content in rats. 


\section{Discussion}

Gastric ulcers are caused by an imbalance between damaging forces and mucosal defenses. Gastric ulceration occurs when mucosal defenses fail. ${ }^{2}$ In this study, PPE showed anti-gastric ulcer activity in the experimental models, including $\mathrm{EtOH} / \mathrm{HCl}-$, indomethacin-, and restraint water immersion stress-induced gastric ulcers in rats.

Ethanol produces necrotic lesions by direct necrotizing action which in turn decreases defensive factors (the production of mucus and secretion of bicarbonate), increases lipid peroxidation, and decreases superoxide dismutase, GSH levels, and catalase. Additionally, $\mathrm{HCl}$ causes strong damage to the gastric mucosa. ${ }^{19,20}$

Nonsteroidal anti-inflammatory drugs (NSAIDs) such as indomethacin cause gastric ulcers through their ability to block cyclooxygenase-1 and cyclooxygnase-2, thereby inhibiting $P G$ production. The pathogenesis of the NSAIDs-induced gastric damage also involves decreased secretion of bicarbonate and mucus, decreased mucosal blood flow, increased acid and pepsinogen secretion, neutrophil infiltration and alterations of microvascular structures. Reactive oxygen species, such as hydroxyl radicals and superoxide radical anions, are believed to play a major role in the patho-genesis of NSAIDs-induced gastric damage. Indomethacin-induced ulcers in rats is a standard model for evaluating the protective effects of compounds against NSAIDs-induced gastric damage. ${ }^{19,21}$

Stress is a physiological response caused by the disruption of homeostasis. Stress-induced gastric ulcer is a typical sample of a stress-associated organ injury. ${ }^{22}$ Water immersion induces stress and causes gastric ulcers by a stimulation of gastric acid secretion and a reduction in mucosal microcirculation and mucus content. ${ }^{19}$ An increase in gastric acid secretion would be expected to be an important factor in ulceration during water immersion. ${ }^{22}$

The present study showed that the PPE-treated group reduced gastric volume but did not affect gastric
$\mathrm{pH}$, total acidity or gastric acid secretion rate. This suggests that anti-secretory action is not likely to be the antigastric ulcer activity of PPE.

Gastric mucus plays a major role as a protective factor against gastrointestinal damage. It consists of a viscous, adherent, elastic, and gel formed by glycoproteins and water that protects the entire gastrointestinal mucosa. Gastric mucus acts as an antioxidant, decreasing mucosal damage mediated by oxygen free radicals. The protective effects of the mucus barrier depend on the gel structure and the layer of the mucosal surface. Thus, gastric wall mucus determination is useful for indicating gastric mucus secretion. ${ }^{19,23}$ PPE significantly promoted gastric mucus content in the $\mathrm{EtOH} / \mathrm{HCl}$ model, which suggests that the main gastroprotective activity of PPE is related to the protection of gastric mucus.

\section{Conclusion}

This study demonstrates that the water extract of Pseuderanthemum palatiferum possesses an antigastric ulcer activity which is related to the preservation of gastric mucus rather than to the inhibition of gastric acid secretion.

\section{Acknowledgement}

This study was supported by the Faculty of Medicine Research Fund, Faculty of Medicine, Chiang Mai University, Chiang Mai, Thailand (Grant no. 43/2558).

\section{References}

1. Padee P, Nualkaew S. Current information of medicinal plants: Pseuderanthemum palatiferum (Ness) Radlk. Jhs 2009;18: 131-8.

2. Dieu HK, Loc CB, Yamasaki S, Hirata Y. The ethnobotanical and botanical study on Pseuderanthemum palatiferum as a new medicinal plant in the Mekong Delta of Vietnam. Jpn Agr Res Q 2005;39:191-6.

3. Mai HD, Minh HN, Pham VC, Bui KN, Nguyen VH, Chau VM. 
Lignans and other constituents from the roots of the Vietnamese medicinal plant Pseuderanthemum palatiferum. Planta Med Lett 2011;77:951-4.

4. Petsangkrit N, Kittipongpatana N. Establishment of Pseuderanthemum palatiferum (Ness) radlk callus culture and screening of secondary metabolite production. Int J Pharm Pharm Sci 2015;8:275-80

5. Chayarop K, Peungvicha P, Wongkrajang Y, Chuakul W, Amnuoypol S, Temsiririrkkul R. Pharmacognostic and phytochemical investigations of Pseuderanthemum palatiferum (Nees) Radlk. ex Lindau Leaves. Phcog J 2011;3:18-23.

6. Khonsung $\mathrm{P}$, Panthong A, Chiranthanut N, Intahphuak S. Hypotensive effect of the water extract of the leaves of Pseuderanthemum palatiferum. J Nat Med 2011;65:551-8.

7. Giang PM, Son PT. Phytochemical study on Pseuderanthemum (NEES) RADLK. Acanthaceae J Chem 2003;41:115-8.

8. Mota KS, Dias GE, Pinto ME, Luiz-Ferreira A, Souza-Brito AR, Hiruma-Lima CA, et al. Flavonoids with gastroprotective activity. Molecules 2009;14:979-1012.

9. Mizui T, Doteuchi M. Effect of polyamines on acidified ethanolinduced gastric lesions in rats. Jpn J Pharmacol 1983;33:93945.

10. Sohn YA, Hwang SA, Lee SY, Hwang IY, Kim SW, Kim SY, et al. Protective effect of liriodendrin isolated from Kalopanax pictus against gastric injury. Biomol Ther 2015;23:53-9.

11. Takagi K, Kasuya $Y$, Watanabe K. Studies on the drugs for peptic ulcers. A reliable method for producing stress ulcers in rats. Chem Pharm Bull 1964;12:465-72.

12. Kudryavtsev KV, Markevich AO, Virchenko OV, Falalyeyeva TM, Beregova TV, Ostapchenko LI, et al. Pharmacological correction of stress-induced gastric ulceration by novel small-molecule agents with antioxidant profile. Sci World $J$ 2014;217039:1-6.

13. Djahanguiri $B$. The production of acute gastric ulceration by indomethacin in the rat. Scand J Gastroenterol 1969;4:265-7.

14. Nwafor PA, Okwuasaba FK, Binda LG. Antidiarrhoeal and antiulcerogenic effects of methanolic extract of Asparagus pubescens root in rats. J Ethnopharmacol 2000;72:421-7.
15. Shay H. A simple method for the uniform production of gastric ulceration in the rat. Gastroenterology 1945;5:43-61.

16. Souza R, Cardoso M, Menezes C, Silva J, De Sousa D, Batista J. Gastroprotective activity of alpha-terpineol in two experimental models of gastric ulcers in rats. DARU J Pharm Sci 2011;19: 277-81.

17. Corne SJ, Morrissey SM, Woods RJ. Proceedings: a method for the quantitative estimation of gastric barrier mucus. J Physiol 1974;242:116-7.

18. Tarique M, Siddiqui $\mathrm{HH}$, Khushtar M, Rahman MA. Protective effect of hydro-alcoholic extract of Ruta graveolens Linn. leaves on indomethacin and pylorus ligation-induced gastric ulcer in rats. J Ayurveda Integr Med 2016;7:38-43.

19. Rujjanawate C, Kanjanapothi D, Amornlerdpison D, Pojanagaroon S. Anti-gastric ulcer effect of Kaempferia parviflora. J Ethnopharmacol 2005;102:120-2.

20. Rozza AL, Moraes Tde M, Kushima H, Tanimoto A, Marques MO, Bauab TM, et al. Gastroprotective mechanisms of Citrus lemon (Rutaceae) essential oil and its majority compounds limonene and beta-pinene: involvement of heat-shock protein-70, vasoactive intestinal peptide, glutathione, sulfhydryl compounds, nitric oxide and prostaglandin E(2). Chem Biol Interact 2011; 189:82-9.

21. Perez Y, Oyarzabal A, Mas R, Molina V, Jimenez S. Protective effect of D-002, a mixture of beeswax alcohols, against indomethacin-induced gastric ulcers and mechanism of action. J Nat Med 2013;67:182-9.

22. Soni H PS, Paul A, Patel G. Evaluation of gastro-protective effect of pep-up tablet and pep-up syrup on water immersion plus restraint stress-induced gastric ulcer in rats. Int $\mathrm{J}$ Herb Med 2014;2:27-30.

23. Coelho-de-Souza AN, Lahlou S, Barreto JE, Yum ME, Oliveira $A C$, Oliveira HD, et al. Essential oil of Croton zehntneri and its major constituent anethole display gastroprotective effect by increasing the surface mucous layer. Fundam Clin Pharmacol 2013;27:288-98. 